\begin{tabular}{c} 
Volume and Issues Obtainable at Center for Sustainability Research and Consultancy \\
Journal of Accounting and Finance in Emerging Economies \\
ISSN: 2519-0318 ISSN (E) 2518-8488 \\
Volume 6: Issue 1 March 2020 \\
¿SRᄃ \\
Journal homepage: www.publishing.globalcsrc.org/jafee \\
\hline
\end{tabular}

\title{
Expounding Dynamics of Tacit Knowledge Critical to Credit Decision Making: Juxtaposed Findings of GRA and RIDIT
}

\author{
${ }^{1}$ Abdul Basit, ${ }^{2}$ Tehmina Fiaz Qazi, ${ }^{3}$ Abdul Aziz Khan Niazi \\ ${ }^{1}$ Academics Head, Lahore Institute of Science \& Technology, Lahore, Pakistan: abasit_shahbaz@yahoo.com \\ ${ }^{2}$ Assistant Professor, IB\&M, University of Engineering and Technology, Lahore, Pakistan: \\ tehmina.qazi@gmail.com \\ ${ }^{3}$ Assistant Professor, IB\&M, University of Engineering \& Technology, Lahore, Pakistan: azizniazi@ uet.edu.pk
}

\begin{tabular}{l} 
ARTICLE DETAILS \\
\hline History \\
Revised format: February 2020 \\
Available Online: March 2020
\end{tabular}

\section{Keywords}

Knowledge Management, Banks, GRA, RIDIT, Pakistan

\section{JEL Classification: \\ D80, E58, E59}

\begin{abstract}
This study explores importance of Tacit Knowledge (TK) sharing for formal loan makers in Pakistan. Main objective of the study is to expound, conceptualize and hierarchicalize the factors of TK critical to credit decision making. The study follows positivist approach and overall research design consists of literature review, field survey and data analyses. Data was collected from credit officers of Pakistani banks. Following the triangulation approach for confirmation and comparison of results, multiple techniques viz EFA, GRA and RIDIT were employed. Results of EFA showed that there are eight major dynamics of TK. Findings of GRA revealed that TK about recovery of loans is the most important factor hence occupies the highest GRA rank, whereas, the TK about resources of borrowers occupies the lowest rank. RIDIT analysis showed that TK about multitude of business sectors is the most important factor hence occupies the highest RIDIT rank, whereas, TK about capacity to repay the loans occupies the lowest rank. Juxtaposition of results of GRA and RIDIT revealed that TK gained during recovery of loans is one of the most important factors. It is a seminal study in the area of knowledge management particularly in context of Pakistani banks based on original data collected in field setting. The study gives insight of critical factors of TK, which has high value for credit personnel in banks. The results are useful for decision makers in banks, academicians and researchers.
\end{abstract}

\section{OPEN ACCESS}

(C) 2020 The authors, under a Creative Commons Attribution-Non

Commercial 4.0

Corresponding author's email address: azizniazi@ uet.edu.pk

Recommended citation: Basit, A., Qazi, T. F. \& Niazi, A. A. K., (2020). Expounding Dynamics of Tacit Knowledge Critical to Credit Decision Making: Juxtaposed Findings of GRA and RIDIT. Journal of Accounting and Finance in Emerging Economies, 6 (1), 87-106

DOI: $10.26710 /$ jafee.v6i1.1044

\section{Introduction}


There is no standardized way to run businesses be them that of even of same type. In ancient times, materials, assets and labor have been key factors for creating competitive advantage but in modern era of technology leveraging knowledge is key to success (Koskinen \& Vanharanta, 2002). Knowledge is now an important tool for decision-making and it is a differentiator for competitive advantage (Fan \& $\mathrm{Ku}$, 2010; Johannessen, Olaisen, \& Olsen, 2003; McIver \& Lepisto, 2017). How you convert your experience into strategic action plans is considered as a critical factor for sustaining competitive position. Knowledge Management (KM) has emerged as a domain of study. It is not restricted to human resource and information technology but linked with strategic decision-making and policy development of organization. It helps organization to tailor critical resources according to business requirements (Wyatt, 2001). Knowledge is created through interaction of employees while working in organizations (Malik \& Garg, 2017; Zhang, Long, Wang, \& Tang, 2015). When groups of people share their experiential knowledge on a specific issue, the knowledge is created that eventually helps an organization to learn and enhance its capabilities. Communities of practice are common source of capturing and sharing knowledge. Where there is culture of knowledge sharing organizations thrive but where individuals are not willing to share knowledge success of organization is jeopardized (Gubbins et al., 2012; Jordão \& Novas, 2017).

In this era of mass production, business firms often borrow money from banks. Banks being formal money lenders strive to verify information about borrowers. They consider effective screening and monitoring of borrower vital for granting loans. Banks try to gain maximum knowledge about borrowers' behaviors to reduce credit risk. Comprehensive and standard set of documents is used to get information about borrowers for reducing uncertainty of loan repayments. Nevertheless, challenges remain particularly when borrower is a small business unit or a new startup and explicit information is insufficient. Such borrowers normally do not have longer credit history. Lack of documented knowledge about these customers makes it difficult for lenders to assess cases of such loans. Since credit decisions are subject to information provided by borrowers which varies from case to case, therefore, role of loan makers' experiential knowledge become critical. Lenders assess cases of loans in light of their experience and make analysis on the basis of questions they ask from borrowers about their intentions to use loan. It is possible now to convert some of one's tacit into explicit knowledge with help of available techniques of knowledge explication.

Banks encourage employees to collect information about borrowers and use different tactics for inducing them to share their experiential knowledge. They encourage to develop cross-functional teams for dissemination of TK (Basit, Tahir, Khan, \& Latif, 2017). TK is now a very critical and conclusive for formal lenders (Arnal \& Burwood, 2003). It plays a decisive role implicitly, however, sharing and use of TK is not easy, there are multiple barriers for TK sharing. These factors include lack of trust, communication and competition culture etc. (Cumberland \& Githens, 2012; Le \& Lei, 2017; Saini, Arif, $\&$ Kulonda, 2018). For intra bank and borrower-lender TK sharing, it is very important to have an effectbased trust, which will help bank managers to use TK in decision-making (Becerra, Lunnan, \& Huemer, 2008; Rahman, Mannan, Hossain, Zaman, \& Hassan, 2018). Furthermore, hierarchy of an organization directly influences the sharing of TK i.e. how much experience one (information provider) have (Joia \& Lemos, 2010).

TK is not very difficult to ascertain and utilize since it is comprised of attitudes and experiences one may have faced. It is, however, not difficult to relate one's experience to a situation one is facing. Almost two third of total TK is received/collected from face to face communication, stories and knowledge incubation (Bretschneider \& Zogaj, 2016). Information technology has warranted to effectively utilize knowledge, 
particularly, TK in decision-making (Martinez-Conesa, Soto-Acosta, \& Carayannis, 2017). TK can be explicated through observations and implementing verbal protocols (Holford, 2018). It can be shared through face-to-face conversations, modern communication soft/hardware like worldwide webs, phones, mobiles and other social media (Ryan \& O'Connor, 2013). In contrast, documented knowledge is very easy to use but this depends on organizational culture, people's cooperation and their mutual trust (Holste \& Fields, 2010; Sasaki, 2017). Appropriate utilization of knowledge helps organizations to heal their network by breaking down silo walls and it helps to solve problems proactively. In past, companies did not have to struggle hard, because, people seldom leave the company and knowledge used to remain with the company, which eventually used to transfer to new employees. But now, when people are frequently switching jobs, it has become inevitable for a company to save its TK (the valuable asset). Importance of TK is increasing day by day and loan makers come up with their own set of questions to get out as much details as possible. TK automatically reduces the overall credit risks, as bankers know more about direction and status of borrowers. In our research, we have focused the importance of TK over the documented knowledge (i.e. explicit knowledge). It reviews the renewed importance of TK sharing and it can be used implicitly to make wiser decision in sanctioning of loans. TK sets up the direction of a company, which eventually helps a lender to analyze the ground situation of the organization (Jasimuddin, Klein, \& Connell, 2005). Evaluation of TK is becoming important, where innovations are taking place. The explicit method is only supporting the pre-defined things in the industry, which are not considered to be updated according to modern requirements. The intention of this paper is to appraise the importance of TK and its intra bank sharing. This study will help loan makers to analyze the risk levels and intentions of the borrower to use this loan, wherein the decision is subject to provided information that varies from case to case. The research paper has expounded the dimensions of TK, conceptualized and hierarchicalized various factors that loan makers take into account in making decision to sanction loan. It creates link between TK sharing and lenders' decision-making practices since TK plays critical role to assessing the borrowers' loan applications. Remaining part of the study consists of literature review, methodology, analysis and interpretation, discussion and conclusion.

\section{Literature Review}

$\mathrm{KM}$ is a complex term, many definitions of $\mathrm{KM}$ have been developed and published but there is no consensus upon its exact definition (Firestone, 2008). However, importance of KM is beyond any doubt, as it has emerged as a distinct multi-discipline scientific field (Qiu \& Lv, 2014). Therefore, KM programs cannot be confined to a particular department, organization, or area of study. It has become essentially important to manage/share it and must be included in the organization's strategic management for adding value (Chuang, Jackson, \& Jiang, 2016; Scarso \& Bolisani, 2010; Shujahat et al., 2017). Living in knowledge-based global economy, knowledge is constantly growing and competitiveness of an organization is inherently linked to keep pace with growing knowledge and accelerate the knowledge transfer (Farooq, 2018). There are two dimensions of knowledge one is termed as documented (i.e. explicit) and other as undocumented knowledge (i.e. tacit). There is a wide spread agreement on the definition of Explicit Knowledge (EK) and is well documented in literature but upon TK definition, there is a disagreement (McAdam, Mason, \& McCrory, 2007). It is pertinent to mention here the brief of EK and TK while keep in mind the scope of study. EK is known, structured information, resides in documents, policies, processes, repositories and databases (Alavi \& Leidner, 2001; Lawson \& Lorenzi, 1999; Minna \& Aino, 2005; Mohamed, Stankosky, \& Murrey, 2006; Nonaka \& Takeuchi, 1995). EK can be transferred through many different ways including physical as well as electronic transfer. TK is an intangible resource, embedded in mind, hard to articulate, recognize and capture (Ambrosini \& Bowman, 2001; Foss, Schum, \& Rothenberg, 2006; Garrick \& Chan, 2017; Klein, 2008; Nonaka \&Takeuchi, 1995; Polanyi, 1966). TK is embedded in a social relation and normally transferred through meetings, observations and direct contact. As TK is embedded in the mind and it is unwritten, hidden and unspoken, so it is obtained through interaction of individuals in the organization (Mohajan, 2016). 
Nonaka and Takeuchi (1995) further categorize TK in i) cognitive dimensions i.e. human mental models including ideas, values, beliefs and perceptions and ii) technical dimensions i.e. know-how which deal with human skills and expertise but workers do not want to articulate. That is why; the central theme in the field of KM is problem of capturing of TK. Intention to share the TK depends on many factors. A successful TK transfer largely depends upon the organizational structure, employees' intention to share TK and the KM strategy adopted by the organization (Han, 2018; Joia \& Lemos, 2010). One of the most important factors is prevailing the culture of knowledge sharing (Cumberland \& Githens, 2012; Wahda, 2017). The results indicate that trust among employees is prerequisite for sharing of knowledge (Brooke, MohdRasdi, \& Abu Samah, 2017; Park \& Lee, 2014). According to Zhang et al. (2015) good relationship among employees play a pivotal role in sharing of TK. It provides support for the direct relation of motivation and intentions of employees in sharing of EK and TK (Chen, Nunes, Ragsdell, \& An, 2018; Hau, Kim, Lee, \& Kim, 2013). TK is more plausible and nowadays become essential for a loan maker to assess a borrower application. Scientists have revealed that $90 \%$ of the total TK is present in the mind of the employees (Wah, 1996b). It is therefore vital to manage this knowledge. For this purpose, a proposed set of questions can be shared with employees and then compile (Venkitachalam \& Busch, 2012). In connection to this, forms are designed for collecting the documented knowledge from the borrower (Hau et al., 2013). Bank provides training to the loan makers to check and analyze all the documentation. Loan decisions are traditionally based on the industry established principles. However, there is a need to establish a standard procedure where a weigh must be given to the level of TK shared. It is observed that despite the process and standard procedure followed by the lender, the decision taken by loan maker varies according to the experience and nature of the loan maker (Kumar \& Chakrabarti, 2012). Literature review revealed many aspects of knowledge, KM, EK and particularly TK sharing. It includes the behavior or attitude while sharing the knowledge and the extent up to which an individual want to share knowledge. As highlighted, loan makers who are able to leverage the TK are likely to make wise decisions in lending of loans. The review supports the notion that TK sharing practices improve the decision regarding loan making. However, merely sharing of TK is not enough but also its utilization. In changing competitive environment, the ability to recognize, acquire, sharing and utilizing TK is important for effective credit decision-making (Mueller, 2015).

\section{Methodology}

In order to measure the importance of TK sharing, positivist approach has been followed as a philosophy and triangulation as a methodology in analyses. For a scientific research, it is necessary to use wellvalidated and reliable measures. Although many measures have already been developed for important organizational concepts and their psychometric properties have been established by developers but we could not find measures suitable for the study. This study has imposed ranking on the factors of TK important for decision making for giving loans. This, being a unique study of developing a model based on TK sharing in banks, no existing instrument measuring the constructs under study, was found. Therefore, a new suitable instrument was developed i.e. a seven-point Likert type scale " 1 " indicating the least favorable degree of agreement and "7" the most favorable degree of agreement. The scale in exact was: $1=$ very strongly disagree, $2=$ strongly disagree, $3=$ disagree, 4=neutral, 5=agree, 6=strongly agree, $7=$ very strongly agree. The questionnaire was developed with the help of literature review, field surveys, and consultation with academicians and bankers. In order to test the instrument, a pilot study was conducted in Lahore. The responses of thirty bankers from different banks in Lahore were obtained. Descriptive statistics was also generated on SPSS. As the standard deviation of population was not previously known, the standard deviation of pilot study has been used for calculation of sample size. The value of Cronbach's Alpha reliability coefficient for all constructs was checked and found to be above 
0.85 in all cases. The questions were reviewed on the bases of pilot study and after the necessary corrections based on feedback of pilot study; the instrument of measurement was finalized and launched for collecting the data. Principle component analysis was employed for extracting factors and orthogonal rotation with varimax was applied. As latent root criterion was used for extraction of factors, only the factors having latent roots or eigen values greater than one were considered significant; all other factors with latent roots less than one were considered insignificant and disregarded in further analyses. The official language and/or medium of instructions in banks is English and bank officers are mostly graduates or post graduates, therefore, medium of communication is English. The instrument was designed for securing responses through direct undisguised questioning. The constructs measured could only be measured through self-reports (Renzl, 2008) hence the instrument is a self-reporting instrument. Results of any research can only be correct when measures that actually tap the concepts in theoretical framework are accurate. In order to be reasonably sure that the instrument we used in the research does indeed measures the variables that are supposed to, the goodness of measure was tested. In this connection, questionnaire was evaluated by seven experienced bankers and researchers from view point of relevancy, adequacy, simplicity and clarity. How well the results obtained from the use of the measure fit the theories around which the test is designed can be seen from the results of the study.

The research is based on population of more than forty commercial banks scheduled with the central bank of Islamic Republic of Pakistan. Statistical data of the population has been collected from secondary sources. Forty banks operating in Pakistan have above 10,000 branches all over the country. There are almost 2,500 branches of banks operating in four provincial capital cities. Total persons employed in credit and monitoring departments are around 20,000. In order to maintain uniformity of the data some adjustments have been made keeping in view the objective of the study. Due to centralization in decision making for loans at headquarters of the banks (Huang, Sheng, \& Li, 2010; Yeung, 2009) it was considered appropriate to conduct the survey in four provincial capital cities (Lahore, Karachi, Peshawar \& Queta). Non-bank financial institutions and micro finance banks are out of scope of the study.

An exploratory factor analysis was carried out to determine the various factors. We have calculated number of sample branches for sample number of persons in the proportion of total branches to total number of persons employed by using the unitary concept of mathematics. Based on standard deviation of pilot study, sample size of 314 persons was calculated (Malhotra \& Dash, 2010). Following the suggested sample size, 314 questionnaires were floated out of which 293 responses are used for the analysis after data filtrations. We have made assumptions while collection of these responses, which include the certain experience level of respondent, only one response was recorded against every question. Each question has to be properly answered and nothing should be left blank. Where these policies were not followed, we have filtered out that response. In order to ensure the representation of all the forty banks the resultant fractions in cases of ten banks have been treated as one (i.e. at least one branch of each bank selected in sample). The size of sample was adjusted as 133 branches. Keeping in view the response rate, the sample size was increased to 195 branches. A stratified simple random sample has been drawn separately from all strata through a computerized random number generator. We obtained total 195 random numbers of branches with additional number of 62 branches only as against the sample of 133 branches. Reasons being:

To conduct large survey in the banking sector is considered a difficult job. The banks have scattered branch networks and specialized type of public dealing. They follow special code of conduct which is focused towards security and secrecy and access to the core departments like credit, recovery, foreign exchange, etc. of banks is difficult but despite of all that the response rate was quite satisfactory i.e. 93.31\%. In order to record the perceptions of loan makers, we have dispatched the instruments to each sample branch by mail. Pakistan Post Office, Urgent Mail Service (UMS) i.e. the state owned postal 
service was considered appropriate because it is economical, track-able, reliable and speedy medium of communication. Two to three questionnaires were dispatched to each branch through UMS followed by telephone calls. The questionnaires were sent under a covering letter with self-addressed envelope. Subsequently, most of the sample branches were approached in person either by researchers or by the well-informed representatives of the researchers. Few of the branches reported as noncredit branches or the branches having credit functions based at specialized offices. Non-credit branches were replaced (as we have sample with replacement). The branches having credit function in specialized offices other than branch were asked to refer the questionnaires to relevant offices and officers dealing credit of that particular branch in order to get true representative response. Some questionnaires were returned duly completed by post, some were followed over the telephone and were collected with little bit effort, yet some others were got completed after encompassing a lot of efforts. In order to investigate the phenomenon; Exploratory Factor Analysis (EFA), Grey Relational Analysis (GRA) and Relative to an Identified Distribution Integral Transformation (RIDIT) have been employed.

\section{Analysis and Interpretation}

\subsection{Exploratory Factor Analysis (EFA)}

Firstly, exploratory factor analysis was employed in SPSS to find out the factors important in credit decision making. As value of KMO (0.83) is showing significant sampling adequacy so it was proceeded further. Based upon loadings of items eight factors were extracted with twenty-six items out of forty-one items (Annexure I) and each factor was assigned a name as represented by the items being loaded, none of the factor showed low factor loading <.40 as shown in Table 1. Factors having eigen values greater than one were retained and each factor explained pretty good variation. First factor accounted for $21.966 \%$ of variation and other seven extracted factors accounted for 8.366, 5.697, 5.529, 4.381, 4.132, 3.671, 3.397 of variation respectively making it $57.138 \%$ altogether.

Table 1: Exploratory Factor Analysis

\begin{tabular}{|l|c|l|l|l|l|l|l|l|l|l|l|}
\hline \multicolumn{2}{|c|}{ Statements } & $\begin{array}{c}\text { Factor } \\
\mathbf{1}\end{array}$ & $\begin{array}{c}\text { Factor } \\
\mathbf{2}\end{array}$ & $\begin{array}{c}\text { Factor } \\
\mathbf{3}\end{array}$ & $\begin{array}{c}\text { Factor } \\
\mathbf{4}\end{array}$ & $\begin{array}{c}\text { Factor } \\
\mathbf{5}\end{array}$ & $\begin{array}{c}\text { Factor } \\
\mathbf{6}\end{array}$ & $\begin{array}{c}\text { Factor } \\
\mathbf{7}\end{array}$ & $\begin{array}{c}\text { Factor } \\
\mathbf{8}\end{array}$ & Communalities & Reliability \\
\hline KCR -1 & $x_{1}$ & .841 & & & & & & & & .774 & .756 \\
\hline KCR -2 & $x_{2}$ & .686 & & & & & & & & .646 \\
\hline KCR -3 & $x_{3}$ & .595 & & & & & & & & .601 \\
\hline KCR -4 & $x_{4}$ & .586 & & & & & & & & .642 \\
\hline KAUL-1 & $x_{5}$ & .570 & & & & & & & & .457 \\
\hline VK-1 & $x_{6}$ & & .704 & & & & & & & .573 \\
\hline VK-2 & $x_{7}$ & & .684 & & & & & & & .566 \\
\hline VK-3 & $x_{8}$ & & .671 & & & & & & & .572 \\
\hline VK-4 & $x_{9}$ & & .656 & & & & & & & .543 \\
\hline KCD-1 & $x_{10}$ & & & .565 & & & & & & .542 \\
\hline KCD-2 & $x_{11}$ & & & .631 & & & & & & .488 \\
\hline KCD-3 & $x_{12}$ & & & .501 & & & & & & .483 \\
\hline KCD-4 & $x_{13}$ & & & .758 & & & & & & .642 \\
\hline KCD-5 & $x_{14}$ & & & .637 & & & & & & .409 \\
\hline
\end{tabular}




\begin{tabular}{|c|c|c|c|c|c|c|c|c|c|c|c|}
\hline UKD-1 & $x_{15}$ & & & & .709 & & & & & .686 & \multirow{4}{*}{.713} \\
\hline UKD-2 & $x_{16}$ & & & & .777 & & & & & .678 & \\
\hline UKD-3 & $x_{17}$ & & & & .545 & & & & & .469 & \\
\hline UKD-4 & $x_{18}$ & & & & .636 & & & & & .641 & \\
\hline KR-1 & $x_{19}$ & & & & & .657 & & & & .515 & \multirow{3}{*}{.650} \\
\hline KR-2 & $x_{20}$ & & & & & .762 & & & & .660 & \\
\hline KR-3 & $x_{21}$ & & & & & .685 & & & & .618 & \\
\hline $\mathrm{KO}-1$ & $x_{22}$ & & & & & & .699 & & & .602 & \multirow{2}{*}{.645} \\
\hline $\mathrm{KO}-2$ & $x_{23}$ & & & & & & .696 & & & .577 & \\
\hline KAUL-2 & $x_{24}$ & & & & & & & .619 & & .536 & \\
\hline CK-1 & $x_{25}$ & & & & & & & & .520 & .529 & \multirow{2}{*}{.282} \\
\hline CK-2 & $x_{126}$ & & & & & & & & .639 & .569 & \\
\hline $\begin{array}{l}\text { Eigen } \\
\text { Values }\end{array}$ & & 6.590 & 2.510 & 1.709 & 1.659 & 1.314 & 1.239 & 1.101 & 1.019 & & \\
\hline $\begin{array}{l}\% \text { of } \\
\text { Variation }\end{array}$ & & 21.966 & 8.366 & 5.697 & 5.529 & 4.381 & 4.132 & 3.671 & 3.397 & & \\
\hline $\begin{array}{l}\text { Cumulative } \\
\% \text { of } \\
\text { variation }\end{array}$ & & 21.966 & 30.332 & 36.028 & 41.557 & 45.937 & 50.069 & 53.740 & 57.138 & & \\
\hline \multicolumn{12}{|c|}{$\begin{array}{l}\text { - Extraction Method-Principal Component Analysis, Rotation Method-Varimax with Kaiser Normalization } \mathrm{KMO}=0.83 \text {, } \\
\text { Bartlett's Test of SpherIcity: } \mathrm{p}=0.000\left(\mathrm{x}^{2}=2412.26, \mathrm{~d} . \mathrm{f}=435\right) \\
\text { - Abbreviations: } \mathrm{KCP}=\mathrm{Knowledge} \text { of Capacity to Repay, VK=Value of Knowledge, } \mathrm{KCD}=\mathrm{Knowledge} \text { of Customer Dealing, } \\
\text { UKD=Use of Knowledge in Decisions, } \mathrm{KR}=\text { Knowledge of Reputation, } \mathrm{KO}=\text { Knowledge of Ownership, KAUL=Knowledge } \\
\text { of Actual Use of Loans and CK=Contextual Knowledge }\end{array}$} \\
\hline
\end{tabular}

\subsection{Grey Relational Analysis (GRA)}

GRA has been performed as follows: d_Om,)

Generated reference data series by using formula $x_{-} 0=\left(d_{-} \_1 \quad \llbracket, d \rrbracket \_(02) \llbracket, d \rrbracket \_(03), \ldots \ldots\right.$

Generated comparison data series by using formula $x_{-} \mathrm{i}=\left(\mathrm{d} \_\mathrm{i} 1 \llbracket, \mathrm{d} \rrbracket \_(\mathrm{i} 2) \llbracket, \mathrm{d} \rrbracket \_(\mathrm{i} 3), \ldots . . \mathrm{d} \_\mathrm{im}\right.$,)

Computed the difference data series by using formula $\Delta_{-} \mathrm{i}=\left(\mid\left(\mathrm{d} \_01-\mathrm{d} \_(\mathrm{i} 1) \mid\right.\right.$, 『|d】_02-d_(i2 ) $\mid$, 『|d』_03-d_(i3 ) ) |,... d__om-d_(im ) $\mid$ )

Found global maximum value and minimum value in the difference data series by using formula $\Delta_{-} \max =\forall^{\wedge} \max \left(\max \Delta_{-} i\right)$ for maximum and $\Delta_{-} \min =\forall^{\wedge} \min \left(\min \Delta_{-} \mathrm{i}\right)$ for minimum

Transformed each data point in each data series to grey relational coefficient by using formula $\gamma_{-} \mathrm{i}$ $(\mathrm{j})=\left(\Delta \_\min +\varsigma \Delta_{-} \max \right) /\left(\Delta \_\mathrm{i}(\mathrm{j})+\varsigma \Delta_{-} \max \right)$

Where:

$\gamma_{-}(\mathrm{i}(\mathrm{j}))=$ grey relational coefficient

$\Delta_{-} \min =$ minimum data point available in difference data series

$\Delta_{-} \max =$ maximum data point available in difference data series. 
$\mathrm{V}=0.5$ which compensate the effect of $\Delta \_$maxin data set and its value can be taken between 0 and 1 but generally it is 0.5 .

$\Delta \_\mathrm{i}(\mathrm{j})=\mathrm{j}^{\wedge}$ th value in difference data set.

Computed grey relational grade for each difference data series by using formula $\Gamma_{-} \mathrm{i}=1 / \mathrm{m}$ $\sum(n=1)^{\wedge} m_{\text {i... }} \gamma_{-} i(n)$

Sorted grey relational grade values in ascending order Generated reference data series from the responses collected by way of field survey as a first step Table 2

Table 2: Data Series

\begin{tabular}{|c|l|l|l|l|l|l|l|l|l|l|l|}
\hline Cases & $\boldsymbol{x}_{\mathbf{1}}$ & $\boldsymbol{x}_{\mathbf{2}}$ & $\boldsymbol{x}_{\mathbf{3}}$ & - & - & $\boldsymbol{x}_{\mathbf{2 1}}$ & $\boldsymbol{x}_{\mathbf{2 2}}$ & $\boldsymbol{x}_{\mathbf{2 3}}$ & $\boldsymbol{x}_{\mathbf{2 4}}$ & $\boldsymbol{x}_{\mathbf{2 5}}$ & $\boldsymbol{x}_{\mathbf{2 6}}$ \\
\hline $\boldsymbol{d}_{\mathbf{1}}$ & 7 & 7 & 6 & - & - & 6 & 6 & 6 & 7 & 6 & 6 \\
\hline $\boldsymbol{d}_{\mathbf{2}}$ & 2 & 3 & 6 & - & - & 1 & 7 & 4 & 3 & 2 & 7 \\
\hline $\boldsymbol{d}_{\mathbf{3}}$ & 3 & 6 & 6 & - & - & 3 & 2 & 6 & 7 & 5 & 3 \\
\hline $\boldsymbol{d}_{\mathbf{4}}$ & 2 & 2 & 4 & - & - & 1 & 1 & 6 & 7 & 2 & 2 \\
\hline- & - & - & - & - & - & - & - & - & - & - & - \\
\hline- & - & - & - & - & - & - & - & - & - & - & - \\
\hline $\boldsymbol{d}_{\mathbf{2 8 7}}$ & 5 & 6 & 6 & - & - & 5 & 6 & 6 & 7 & 6 & 5 \\
\hline $\boldsymbol{d}_{\mathbf{2 8 8}}$ & 6 & 6 & 6 & - & - & 6 & 5 & 7 & 5 & 6 & 6 \\
\hline $\boldsymbol{d}_{\mathbf{2 8 9}}$ & 4 & 5 & 6 & - & - & 7 & 7 & 7 & 6 & 7 & 5 \\
\hline $\boldsymbol{d}_{\mathbf{2 9 0}}$ & 4 & 6 & 7 & - & - & 6 & 6 & 5 & 6 & 6 & 7 \\
\hline $\boldsymbol{d}_{\mathbf{2 9 1}}$ & 3 & 4 & 5 & - & - & 4 & 6 & 6 & 5 & 6 & 2 \\
\hline
\end{tabular}

Generated comparison data series by way of setting very strongly agree (i.e. 7 larger the acceptable) being reference series as second step and prepared Table 3

Table 3: Comparison Data Series

\begin{tabular}{|c|l|l|l|l|l|l|l|l|l|l|l|l|}
\hline Cases & $\boldsymbol{x}_{\mathbf{0}}$ & $\boldsymbol{x}_{\mathbf{1}}$ & $\boldsymbol{x}_{\mathbf{2}}$ & $\boldsymbol{x}_{\mathbf{3}}$ & - & - & $\boldsymbol{x}_{\mathbf{2 1}}$ & $\boldsymbol{x}_{\mathbf{2 2}}$ & $\boldsymbol{x}_{\mathbf{2 3}}$ & $\boldsymbol{x}_{\mathbf{2 4}}$ & $\boldsymbol{x}_{\mathbf{2 5}}$ & $\boldsymbol{x}_{\mathbf{2 6}}$ \\
\hline $\boldsymbol{d}_{\mathbf{1}}$ & 7 & 7 & 7 & 6 & - & - & 6 & 6 & 6 & 7 & 6 & 6 \\
\hline $\boldsymbol{d}_{\mathbf{2}}$ & 7 & 2 & 3 & 6 & - & - & 1 & 7 & 4 & 3 & 2 & 7 \\
\hline $\boldsymbol{d}_{\mathbf{3}}$ & 7 & 3 & 6 & 6 & - & - & 3 & 2 & 6 & 7 & 5 & 3 \\
\hline $\boldsymbol{d}_{\mathbf{4}}$ & 7 & 2 & 2 & 4 & - & - & 1 & 1 & 6 & 7 & 2 & 2 \\
\hline- & - & - & - & - & - & - & - & - & - & - & - & - \\
\hline- & - & - & - & - & - & - & - & - & - & - & - & - \\
\hline $\boldsymbol{d}_{\mathbf{2 8 7}}$ & 7 & 5 & 6 & 6 & - & - & 5 & 6 & 6 & 7 & 6 & 5 \\
\hline $\boldsymbol{d}_{\mathbf{2 8 8}}$ & 7 & 6 & 6 & 6 & - & - & 6 & 5 & 7 & 5 & 6 & 6 \\
\hline $\boldsymbol{d}_{\mathbf{2 8 9}}$ & 7 & 4 & 5 & 6 & - & - & 7 & 7 & 7 & 6 & 7 & 5 \\
\hline $\boldsymbol{d}_{\mathbf{2 9 0}}$ & 7 & 4 & 6 & 7 & - & - & 6 & 6 & 5 & 6 & 6 & 7 \\
\hline $\boldsymbol{d}_{\mathbf{2 9 1}}$ & 7 & 3 & 4 & 5 & - & - & 4 & 6 & 6 & 5 & 6 & 2 \\
\hline
\end{tabular}


Computed the difference data series by taking the absolute difference of each data point with reference as a step three and prepared Table 4

Table 4: Difference Data Series

\begin{tabular}{|l|l|l|l|l|l|l|l|l|l|l|}
\hline$\Delta_{\mathbf{1}}$ & $\Delta_{\mathbf{2}}$ & $\Delta_{\mathbf{3}}$ & - & - & \multicolumn{1}{|c|}{$\Delta_{\mathbf{2 1}}$} & \multicolumn{1}{|c|}{$\Delta_{\mathbf{2 2}}$} & \multicolumn{1}{|c|}{$\Delta_{\mathbf{2 3}}$} & $\Delta_{\mathbf{2 4}}$ & $\Delta_{\mathbf{2 5}}$ & $\Delta_{\mathbf{2 6}}$ \\
\hline 0 & 0 & 1 & - & - & 1 & 1 & 1 & 0 & 1 & 1 \\
\hline 5 & 4 & 1 & - & - & 6 & 0 & 3 & 4 & 5 & 0 \\
\hline 4 & 1 & 1 & - & - & 4 & 5 & 1 & 0 & 2 & 4 \\
\hline 5 & 5 & 3 & - & - & 6 & 6 & 1 & 0 & 5 & 5 \\
\hline- & - & - & - & - & - & - & - & - & - & - \\
\hline- & - & - & - & - & - & - & - & - & - & - \\
\hline 2 & 1 & 1 & - & - & 2 & 1 & 1 & 0 & 1 & 2 \\
\hline 1 & 1 & 1 & - & - & 1 & 2 & 0 & 2 & 1 & 1 \\
\hline 3 & 2 & 1 & - & - & 0 & 0 & 0 & 1 & 0 & 2 \\
\hline 3 & 1 & 0 & - & - & 1 & 1 & 2 & 1 & 1 & 0 \\
\hline 4 & 3 & 2 & - & - & 3 & 1 & 1 & 2 & 1 & 5 \\
\hline
\end{tabular}

Calculated global maximum and global minimum as a fourth step in the difference data series i.e. $\Delta_{\max }=$ $\forall^{\max }\left(\max \Delta_{i}\right)=6$ for maximum and $\Delta_{\min }=\forall^{\min }\left(\min \Delta_{i}\right)=0$ for minimum.

Transformed each data point in each data series to grey relational coefficient as a fifth step Table 5

Table 5: Grey Relational Coefficient

\begin{tabular}{lllllllllll}
\hline \multicolumn{1}{c}{$\boldsymbol{\gamma}_{\mathbf{1}}$} & \multicolumn{1}{c}{$\boldsymbol{\gamma}_{\mathbf{2}}$} & \multicolumn{1}{c}{$\boldsymbol{\gamma}_{\mathbf{3}}$} & - & - & $\boldsymbol{\gamma}_{\mathbf{2 1}}$ & \multicolumn{1}{c}{$\boldsymbol{\gamma}_{\mathbf{2 2}}$} & \multicolumn{1}{c}{$\boldsymbol{\gamma}_{\mathbf{2 3}}$} & \multicolumn{1}{c}{$\boldsymbol{\gamma}_{\mathbf{2 4}}$} & \multicolumn{1}{c}{$\boldsymbol{\gamma}_{\mathbf{2 5}}$} & \multicolumn{1}{c}{$\boldsymbol{\gamma}_{\mathbf{2 6}}$} \\
\hline 1 & 1 & 0.75 & - & - & 0.75 & 0.75 & 0.75 & 1 & 0.75 & 0.75 \\
0.38 & 0.43 & 0.75 & - & - & 0.33 & 1 & 0.5 & 0.43 & 0.38 & 1 \\
0.43 & 0.75 & 0.75 & - & - & 0.43 & 0.38 & 0.75 & 1 & 0.6 & 0.43 \\
0.38 & 0.38 & 0.5 & - & - & 0.33 & 0.33 & 0.75 & 1 & 0.38 & 0.38 \\
- & - & - & - & - & - & - & - & - & - & - \\
- & - & - & - & - & - & - & - & - & - & - \\
0.6 & 0.75 & 0.75 & - & - & 0.6 & 0.75 & 0.75 & 1 & 0.75 & 0.6 \\
0.75 & 0.75 & 0.75 & - & - & 0.75 & 0.6 & 1 & 0.6 & 0.75 & 0.75 \\
0.5 & 0.6 & 0.75 & - & - & 1 & 1 & 1 & 0.75 & 1 & 0.6 \\
0.5 & 0.75 & 1 & - & - & 0.75 & 0.75 & 0.6 & 0.75 & 0.75 & 1 \\
0.43 & 0.5 & 0.6 & - & - & 0.5 & 0.75 & 0.75 & 0.6 & 0.75 & 0.38 \\
\hline
\end{tabular}

Computed grey relational grade for each difference data series as a sixth step (Table 6). 
Table 6: Grey Relational Grade

\begin{tabular}{|l|c|c|c|c|c|c|c|c|c|c|c|c|}
\hline Statements & $\boldsymbol{x}_{\mathbf{1}}$ & $\boldsymbol{x}_{\mathbf{2}}$ & $\boldsymbol{x}_{\mathbf{3}}$ & $\boldsymbol{x}_{\mathbf{4}}$ & - & - & $\boldsymbol{x}_{\mathbf{2 1}}$ & $\boldsymbol{x}_{\mathbf{2 2}}$ & $\boldsymbol{x}_{\mathbf{2 3}}$ & $\boldsymbol{x}_{\mathbf{2 4}}$ & $\boldsymbol{x}_{\mathbf{2 5}}$ & $\boldsymbol{x}_{\mathbf{2 6}}$ \\
\hline $\begin{array}{l}\text { GRA } \\
\text { Grade }\end{array}$ & 0.614 & 0.634 & 0.717 & 0.494 & - & - & 0.648 & 0.631 & 0.634 & 0.664 & 0.661 & 0.648 \\
\hline
\end{tabular}

Sorted grey relational grades in ascending order as a seventh step (Table 7).

Table 7: Grey Relational Grades and Ranks

\begin{tabular}{|l|l|l|}
\hline Statements & GRA Grade & GRA Rank \\
\hline KCD-5 & 0.789 & 1 \\
\hline VK-4 & 0.747 & 2 \\
\hline KCR -3 & 0.717 & 3 \\
\hline KAUL-1 & 0.700 & 4 \\
\hline UKD-1 & 0.699 & 5 \\
\hline KCD-2 & 0.698 & 6 \\
\hline KCD-3 & 0.698 & 7 \\
\hline KCD-4 & 0.695 & 8 \\
\hline UKD-2 & 0.685 & 9 \\
\hline UKD-4 & 0.684 & 10 \\
\hline KR-2 & 0.675 & 11 \\
\hline KCD-1 & 0.672 & 12 \\
\hline UKD-3 & 0.669 & 13 \\
\hline KAUL-2 & 0.664 & 14 \\
\hline CK-1 & 0.661 & 15 \\
\hline KR-1 & 0.658 & 16 \\
\hline KR-3 & 0.649 & 17 \\
\hline CK-2 & 0.648 & 18 \\
\hline VK-1 & 0.638 & 19 \\
\hline KO-2 & 0.634 & 20 \\
\hline KCR -2 & 0.633 & 21 \\
\hline KO-1 & 0.631 & 22 \\
\hline VK-2 & 0.622 & 23 \\
\hline KCR -1 & 0.614 & 24 \\
\hline VK-3 & 0.518 & 25 \\
\hline KCR -4 & 0.494 & 26 \\
\hline & & \\
\hline & & \\
\hline
\end{tabular}

\subsection{Relative to an Identified Distribution Integral Transformation (RIDIT)}

RIDIT is applied as follows: 


\subsubsection{Computed RIDIT for the reference data set:}

a. Selected a population (i.e. total responses of survey taken on seven point scale) to serve as a reference data set

b. Calculated frequency for every category of response i.e. $f_{j}$ where $j=1,2,3, \ldots \ldots$.

c. Computed mid-point of frequencies by using formula $F_{1}=\frac{1}{2} f_{1}$

d. Computed accumulated frequency for each category of responses by using formula $F_{j}=\frac{1}{2} f_{j}+$ $\sum_{k=1}^{j-1} f_{k}$

e. Computed RIDIT value for each category of responses in the reference data set by using formula $R_{j}=\frac{F_{j}}{N}$

Table 8: RIDITS for the Reference Data Set

\begin{tabular}{|c|l|l|l|l|l|l|l|l|}
\hline $\begin{array}{l}\text { Statements } \\
(\mathrm{x})\end{array}$ & $\begin{array}{l}\text { Very } \\
\text { Strongly } \\
\text { Disagree }\end{array}$ & $\begin{array}{l}\text { Strongly } \\
\text { Disagree }\end{array}$ & Disagree & Neutral & Agree & $\begin{array}{l}\text { Strongly } \\
\text { Agree }\end{array}$ & $\begin{array}{l}\text { Very } \\
\text { Strongly } \\
\text { Agree }\end{array}$ & $\boldsymbol{\pi}_{\boldsymbol{i}}$ \\
\hline $\boldsymbol{x}_{\mathbf{1}}$ & 7 & 30 & 38 & 46 & 76 & 55 & 39 & 291 \\
\hline $\boldsymbol{x}_{\mathbf{2}}$ & 2 & 9 & 27 & 53 & 100 & 71 & 29 & 291 \\
\hline $\boldsymbol{x}_{\mathbf{3}}$ & 3 & 9 & 9 & 24 & 78 & 106 & 62 & 291 \\
\hline $\boldsymbol{x}_{\mathbf{4}}$ & 4 & 1 & 9 & 31 & 57 & 113 & 76 & 291 \\
\hline- & - & - & - & & - & - & - & - \\
\hline- & - & - & - & - & - & - & - & - \\
\hline $\boldsymbol{x}_{\mathbf{2 2}}$ & 6 & 8 & 22 & 55 & 86 & 76 & 38 & 291 \\
\hline $\boldsymbol{x}_{\mathbf{2 3}}$ & 7 & 10 & 45 & 39 & 85 & 65 & 40 & 291 \\
\hline $\boldsymbol{x}_{\mathbf{2 4}}$ & 7 & 13 & 26 & 40 & 78 & 76 & 51 & 291 \\
\hline $\boldsymbol{x}_{\mathbf{2 5}}$ & 6 & 12 & 40 & 42 & 86 & 71 & 34 & 291 \\
\hline $\boldsymbol{x}_{\mathbf{2 6}}$ & 4 & 8 & 15 & 31 & 111 & 90 & 32 & 291 \\
\hline $\boldsymbol{f}_{\boldsymbol{j}}$ & 108 & 233 & 482 & 1023 & 2320 & 2065 & 1335 & 7566 \\
\hline $\boldsymbol{F}_{\mathbf{1}}$ & 54 & 116.5 & 241 & 511.5 & 1160 & 1032.5 & 667.5 & \\
\hline $\boldsymbol{F}_{\boldsymbol{J}}$ & 54 & 224.5 & 582 & 1334.5 & 3006 & 5198.5 & 6898.5 & \\
\hline $\boldsymbol{R}_{\boldsymbol{J}}$ & 0.01 & 0.03 & 0.08 & 0.18 & 0.40 & 0.69 & 0.91 & \\
\hline
\end{tabular}

\subsubsection{Computed RIDIT and mean RIDIT for comparison data sets:}

a. Computed RIDIT value for each category of scale items by using formula $r_{i j}=\frac{R_{j} \pi_{i j}}{\pi_{i}}$ where $\pi_{i}=$ $\sum_{k=1}^{n} \pi_{i k}$

b. Computed mean RIDIT for each scale item by using formula $\rho_{i}=\sum_{k=1}^{n} r_{i k}$

c. Computed confidence interval by using formula $\rho_{i} \pm \frac{1}{\sqrt{3 \pi_{i}}}$

d. Tested the hypothesis $\left\{\begin{array}{l}H_{0}: \forall_{i}, \rho_{i}=0.5 \\ H_{a}: \exists_{i}, \rho_{i} \neq 0.5\end{array}\right.$ using Kruskal-Wallis statistics by using formula $W=$ $12 \sum_{i=1}^{m} \pi_{i}\left(\rho_{i}-0.5\right)^{2}$ 
Table 9: RIDITs for Comparison Data Set

\begin{tabular}{|c|c|c|c|c|c|c|c|c|c|c|}
\hline $\begin{array}{l}\text { Statements } \\
\text { (x) }\end{array}$ & V.S.D & S.D & D & $\mathrm{N}$ & A & S.A & V.S.A & $\rho_{\mathrm{i}}$ & L.B & U.B \\
\hline$x_{1}$ & 0.0002 & 0.0031 & 0.0104 & 0.0285 & 0.1045 & 0.1304 & 0.1220 & 0.3991 & 0.3651 & 0.4331 \\
\hline$x_{2}$ & 0.0001 & 0.0009 & 0.0074 & 0.0328 & 0.1375 & 0.1684 & 0.0907 & 0.4377 & 0.4037 & 0.4717 \\
\hline$x_{3}$ & 0.0001 & 0.0009 & 0.0025 & 0.0148 & 0.1072 & 0.2513 & 0.1939 & 0.5708 & 0.5368 & 0.6048 \\
\hline$x_{4}$ & 0.0001 & 0.0001 & 0.0025 & 0.0192 & 0.0784 & 0.2679 & 0.2377 & 0.6058 & 0.5718 & 0.6398 \\
\hline - & - & - & - & - & - & - & - & - & - & - \\
\hline - & - & - & - & - & - & - & - & - & - & - \\
\hline$x_{23}$ & 0.0002 & 0.0010 & 0.0124 & 0.0241 & 0.1168 & 0.1541 & 0.1251 & 0.4338 & 0.3998 & 0.4678 \\
\hline$x_{24}$ & 0.0002 & 0.0013 & 0.0071 & 0.0247 & 0.1072 & 0.1802 & 0.1595 & 0.4804 & 0.4464 & 0.5144 \\
\hline$x_{25}$ & 0.0002 & 0.0012 & 0.0110 & 0.0260 & 0.1182 & 0.1684 & 0.1063 & 0.4313 & 0.3973 & 0.4653 \\
\hline$x_{26}$ & 0.0001 & 0.0008 & 0.0041 & 0.0192 & 0.1526 & 0.2134 & 0.1001 & 0.4903 & 0.4563 & 0.5243 \\
\hline
\end{tabular}

Sorted RIDIT values into ascending order Table 10.

Table 10: RIDIT Valued and Ranks

\begin{tabular}{|l|l|l|}
\hline Items & RIDIT Values & Ridit Rank \\
\hline UKD-1 & 0.659 & 1 \\
\hline KCR -4 & 0.606 & 2 \\
\hline KCD-1 & 0.595 & 3 \\
\hline KCR -3 & 0.571 & 4 \\
\hline UKD-2 & 0.544 & 5 \\
\hline KCD-3 & 0.538 & 6 \\
\hline KAUL-1 & 0.535 & 7 \\
\hline KCD-4 & 0.532 & 8 \\
\hline KCD-5 & 0.532 & 9 \\
\hline UKD-3 & 0.52 & 10 \\
\hline KR-1 & 0.518 & 11 \\
\hline KR-3 & 0.505 & 12 \\
\hline VK-4 & 0.497 & 13 \\
\hline KCD-2 & 0.494 & 14 \\
\hline UKD-4 & 0.491 & 15 \\
\hline CK-2 & 0.490 & 16 \\
\hline KR-2 & 0.480 & 17 \\
\hline KAUL-2 & 0.480 & 18 \\
\hline KO-1 & 0.458 & 19 \\
\hline VK-3 & 0.448 & 20 \\
\hline VK-1 & 0.439 & 21 \\
\hline KCR -2 & 0.438 & 22 \\
\hline KO-2 & 0.434 & 23 \\
\hline CK-1 & 0.431 & 24 \\
\hline & & \\
\hline
\end{tabular}




\begin{tabular}{|l|l|l|}
\hline VK-2 & 0.418 & 25 \\
\hline KCR -1 & 0.399 & 26 \\
\hline
\end{tabular}

Findings of the GRA (i.e. grey relational grade and grey relational rank) and RIDIT (i.e. RIDIT value and RIDIT ranks) are juxtaposed for comparison Table 11

Table 11: Juxtaposition of Findings of GRA and RIDIT

\begin{tabular}{|l|l|l|l|l|}
\hline Items & GRA Grade & GRA Rank & RIDIT Value & RIDIT Rank \\
\hline KCR -1 & 0.614 & 24 & 0.399 & 26 \\
\hline KCR -2 & 0.633 & 21 & 0.438 & 22 \\
\hline KCR -3 & 0.717 & 3 & 0.571 & 4 \\
\hline KCR -4 & 0.494 & 26 & 0.606 & 2 \\
\hline KAUL-1 & 0.7 & 4 & 0.535 & 7 \\
\hline VK-1 & 0.638 & 19 & 0.439 & 21 \\
\hline VK-2 & 0.622 & 23 & 0.418 & 25 \\
\hline VK-3 & 0.518 & 25 & 0.448 & 20 \\
\hline VK-4 & 0.747 & 2 & 0.497 & 13 \\
\hline KCD-1 & 0.672 & 12 & 0.595 & 3 \\
\hline KCD-2 & 0.698 & 6 & 0.494 & 14 \\
\hline KCD-3 & 0.698 & 7 & 0.538 & 6 \\
\hline KCD-4 & 0.695 & 8 & 0.532 & 8 \\
\hline KCD-5 & 0.789 & 1 & 0.532 & 9 \\
\hline UKD-1 & 0.699 & 5 & 0.659 & 1 \\
\hline UKD-2 & 0.685 & 9 & 0.544 & 5 \\
\hline UKD-3 & 0.669 & 13 & 0.52 & 10 \\
\hline UKD-4 & 0.684 & 10 & 0.491 & 15 \\
\hline KR-1 & 0.658 & 16 & 0.518 & 11 \\
\hline KR-2 & 0.675 & 11 & 0.48 & 17 \\
\hline KR-3 & 0.649 & 17 & 0.505 & 12 \\
\hline KO-1 & 0.631 & 22 & 0.458 & 19 \\
\hline KO-2 & 0.634 & 20 & 0.434 & 23 \\
\hline KAUL-2 & 0.664 & 14 & 0.48 & 18 \\
\hline CK-1 & 0.661 & 15 & 0.431 & 24 \\
\hline CK-2 & 0.648 & 18 & 0.49 & 16 \\
\hline
\end{tabular}

The juxtaposition revealed that there is significant difference between rankings of most of the dimensions while some dimensions are quite close in ranking. Only one dimension is found to be on the same rank assigned by two different techniques that is KCD-4 (i.e. I deal with different internal and external communities during recovery process) which is ranked eighth as a result of both techniques as highlighted

\subsubsection{Discussion}

The study attempted to explore the relation of TK sharing and its influence on the loan maker's decision. While going through the formal procedure and depending upon the analysis of borrower data, Loan officer's TK is a key part of loan decision. But the studies on explication, sharing and dynamics of the TK are relatively very few that provides justification of current study. The results of the study indicate that TK is possessed and used in decision making in banks. Evaluation of the measurements used to elicit the data about utilization of TK revealed that TK has multitude of dimensions out of which eight have been 
extracted through principle component analysis. Although principle component analysis preliminary depict reasonable results but still one of the measures KAUL-1 is statistically loaded on factor namely "Knowledge of Capacity to Repay" which is theoretically relevant to "Knowledge of Actual Use of Loans". Reason may be that the language of this statement probably could not be clearly understood by the respondents. Therefore, before using this scale for future research this statement should be improved. Similarly, internal consistency of Contextual Knowledge is statistically does not meet the standard despite of its theoretical validity. Results of the study can be taken as preliminary evidence that in a context without sophisticated credit scoring systems or documentation about the loan applicant, loan officer's personal knowledge about their clients may be invaluable in screening of the borrowers. The strength and importance of TK reflects in facing difficulty for competitors to imitate (Foss et al., 2006). When an organization realizes the strength of its employee's wealth of TK and able to manage it, gets the ultimate progress (Mezghani, Exposito, \& Drira, 2016). Therefore, this paper has focused on the importance of TK sharing that got same rank from both techniques of analysis. Moreover, reward policies are being devised to engage them to stay and motivate to articulate their embedded knowledge. These initiatives will surely beget the culture of sharing of tacit knowledge, resultantly avoiding failures, delays and mistakes and at the end to reap good returns (Arnett \& Wittmann, 2014).

\section{Conclusion}

Millions of dollars have been invested on employees as organizations know they can only grow if their employees have a good exposure and better learning curve. Training of loan officers is much needed for understanding the behavior of the borrowers while sanctioning of the loans, as it must not only be on the basis of documentation but also on the intentions of the borrowers. Therefore, main objective of the study was to expound, conceptualize and hierarchicalize the dynamics of TK critical to credit decision making. EFA, GRA and RIDIT have been employed as techniques of investigation. Results of EFA showed that there are eight major dynamics of TK namely knowledge of capacity to repay, value of knowledge, knowledge of customer dealing, use of knowledge in decisions, knowledge of reputation, knowledge of ownership, knowledge of actual use of loans and contextual knowledge. Findings of GRA revealed that TK about recovery of loans is the most important factor hence occupies the highest GRA rank, whereas, the TK about resources of borrowers occupies the lowest rank. RIDIT analysis showed that TK about multitude of business sectors is the most important factor hence occupies the highest RIDIT rank, whereas, TK about capacity to repay the loans occupies the lowest rank. Juxtaposition of results of GRA and RIDIT revealed that TK gained through dealing with different internal and external communities during recovery of loans is one of the most important factors since it occupies the same rank according to both techniques. The study gives insight of critical factors of TK, which has high value for credit personnel in banks. The results are useful for decision makers in banks, academicians and researchers. This study has contributed towards literature by way of developing scale, extraction of different factors of TK, ranking of measures, identification and confirmation of the most important factors for TK critical. Future research may be conducted in different contexts and with larger samples to enhance the frontiers of contribution of the study.

\section{References}

Alavi, M., \& Leidner, D. E. (2001). Knowledge management and knowledge management systems: Conceptual foundations and research issues. MIS Quarterly, 25(1), 107-136.

Ambrosini, V., \& Bowman, C. (2001). Tacit knowledge: Some suggestions for operationalization. Journal of Management Studies, 38(6), 811-829.

Arnal, S.G., \& Burwood, S. (2003). Tacit knowledge and public accounts. Journal of Philosophy of Education, 37(3), 377-391. 
Arnett, B., \& Wittmann, C. (2014). Improving marketing success: The role of tacit knowledge exchange between sales and marketing. Journal of Business Research, 67, 324-331.

Basit, A., Tahir A., Khan, M.M., Latif, M.I. (2017). TK augmented customer relationship management systems: An empirical investigation. Pakistan journal of Commerce and Social Sciences, 11(3), 1005-1026.

Becerra, M., Lunnan, R., \& Huemer, L. (2008). Trustworthiness, risk, and the transfer of tacit and explicit knowledge between alliance partners. Journal of Management Studies, 45(4), 691-713.

Bretschneider, U., \& Zogaj, S. (2016). Exploring strategies for capturing customer's tacit knowledge in customer integration methods. International Journal of KM, 12(2), 1-19.

Brooke, J., MohdRasdi, R., \& Abu Samah, B. (2017). Modeling knowledge sharing behaviour using self-efficacy as a mediator. European Journal of Training and Development, 41(2), 144-159.

Chen, H., Nunes, M.B., Ragsdell, G., \& An, X. (2018). Extrinsic and intrinsic motivation for experience grounded tacit knowledge sharing in Chinese software organizations. Journal of Knowledge Management, 22(2), 478-498.

Chuang, C.-H., Jackson, S.E., \& Jiang, Y. (2016). Can knowledge-intensive teamwork be managed? Examining the roles of HRM systems, leadership, and tacit knowledge. Journal of management,42(2), 524-54.

Cumberland, D., \& Githens, R. (2012). TK barriers in franchising: Practical solutions. Journal of Workplace Learning, 24(1), 48-58.

Fan, Y.W., \& Ku, E. (2010). Customer focus, service process fit and customer relationship management profitability: The effect of knowledge sharing. The Service Industrial Journal, 30(2), 203-223.

Farooq, R. (2018). A conceptual model of knowledge sharing. International Journal of Innovation Science, 10(2), 238-260.

Firestone, J.M. (2008). On doing knowledge management. Knowledge Management Research \& Practice, 6(1), 1322.

Foss, T., Schum, G., \& Rothenberg, S. (2006). Tacit knowledge transfer and the knowledge disconnect. Journal of Knowledge Management, 10(1), 6-18.

Garrick, J., \& Chan, A. (2017). Knowledge management and professional experience: The uneasy dynamics between tacit knowledge and performativity in organizations. Journal of Knowledge Management, 21(4), 872-884.

Gubbins, C., Corrigan, S., Garavan, T., Connor, C., Leahy, D., Long, D., \& Murphy, E. (2012). Evaluating a tacit knowledge sharing initiative: A case study. European Journal of Training and Development, 36(8), 827847.

Han, S.H. (2018). The antecedents and dimensionality of knowledge-sharing intention: An empirical study of R\&D engineers in a high-performing IT company. European Journal of Training and Development, 42(1/2), 125142.

Hau, Y.S., Kim, B., Lee, H., \& Kim, Y-G. (2013). The effects of individual motivations and social capital on employees' tacit and explicit knowledge sharing intentions. International Journal of Information Management, 33(2), 356-366.

Holford, W.D. (2018). An agential realist perspective on the construction and flow of knowledge: The case of dynamic entanglement and "cuts" within an aircraft engine manufacturing workplace. Journal of Knowledge Management, 22(7), 1442-1470.

Holste, J.S., \& Fields, D. (2010). Trust and tacit knowledge sharing and use. Journal of Knowledge Management, $14(1), 128-140$.

Huang, F., Sheng, Y., \& Li, Z. (2010). Evaluation of Default Risk Based on KMV Model for ICBC, CCB and BOC. International Journal of Economics and Finance, 2(1), 72-80.

Jasimuddin, S., Klein, J., \& Connell, C. (2005). The paradox of using tacit and explicit knowledge: Strategies to face dilemmas. Management Decision, 43(1), 102-112.

Johannessen, J.A., Olaisen, J., \& Olsen, B.R. (2003). Mismanagement of tacit knowledge: The importance of tacit 
knowledge, the danger of information technology, and what to do about it. International Journal of Information Management, 21(1), 3-20.

Joia, L., \& Lemos, B. (2010). Relevant factors for tacit knowledge transfer within organizations. Journal of Knowledge Management, 14(3), 410-427

Jordão, R.V.D., \& Novas, J.C. (2017). Knowledge management and intellectual capital in networks of small-and medium-sized enterprises. Journal of Intellectual Capital, 18(3), 667-692.

Klein, J.H. (2008). Some directions for research in knowledge sharing. Knowledge Management Research and Practice, 6(1), 41-46.

Koskinen, K.U., \& Vanharanta, H. (2002). The role of tacit knowledge in innovation processes of small technology companies. Int. J. Production Economics, 80(1), 57-64.

Lawson, C., \& Lorenzi, E. (1999). Collective learning, tacit knowledge and regional innovative capacity. Regional Studies, 33(4), 305-317.

Le, P.B. \& Lei, H. (2017). How transformational leadership supports knowledge sharing: Evidence from Chinese manufacturing and service firms. Chinese Management Studies, 11(3), 479-497.

Kumar, A., \& Chakrabarti, A. (2012). Bounded awareness and tacit knowledge: Revisiting Challenger disaster. Journal of Knowledge Management, 16(6), 934-949.

Malhotra, N.K., \& Dash, S. (2010). Marketing research: An applied approach, Part II, Chapter 12, 369-365, Published by Dorling Kindersely (India) (Pvt.) Ltd. Licensees Pearson Education South Asia.

Malik, P., \& Garg, P. (2017). The relationship between learning culture, inquiry and dialogue, knowledge sharing structure and affective commitment to change. Journal of Organizational Change Management, 30(4), 610631.

Martinez-Conesa, I., Soto-Acosta, P., \& Carayannis, E.G. (2017). On the path towards open innovation: Assessing the role of knowledge management capability and environmental dynamism in SMEs. Journal of Knowledge Management, 21(3), 553-570.

McIver, D., \&Lepisto, D.A. (2017). Effects of knowledge management on unit performance: Examining the moderating role of tacitness and learnability. Journal of Knowledge Management, 21(4), 796-816.

McAdam, R., Mason, B., \& McCrory, J. (2007). Exploring the dichotomies within the tacit knowledge literature: towards a process of tacit knowing in organizations. Journal of Knowledge Management, 11(2), 43-59.

Mezghani, E., Exposito, E., \& Drira, K. (2016). A collaborative methodology for tacit knowledge management: Application to scientific research. Future Generation Computer Systems, Elsevier, 54(1), 450-455.

Minna, R., \& Aino, H. (2005). Customer knowledge management competence: Towards a theoretical framework. Proceedings of the 38th Hawaii International Conference on System Sciences. IEEE 0-7695-2268-8/05, [Online] Available at: www.hiess.hawaii.edu/home.htm (November 30th, 2016).

Mohajan, H.M. (2016). Sharing of tacit knowledge in organizations: A Review. American Journal of Computer Science and Engineering, 3(2), 6-19.

Mohamed, M., Stankosky, M., \& Murrey, A. (2006). Knowledge Management and information technology: Can they work in perfect harmony? Journal of Knowledge Management, 10(3), 103-116.

Mueller, J. (2015). Formal and informal practices of knowledge sharing between project teams and enacted cultural characteristics. Project Management Journal, 46(1), 53-68.

Nonaka, I., \& Takeuchi, H. (1995). The Knowledge-Creating Company. Oxford University Press.

Park J.G., \& Lee, J. (2014). Knowledge sharing in information systems development projects: Explicating the role of dependence and trust. International Journal of Project Management, 32(1), 153-165.

Polanyi, M. (1966). The Tacit Dimension. Routledge and Kegan Paul, London.

Qiu, J., \& Lv, H. (2014). An overview of knowledge management research viewed through the web of science (1993-2012). Aslib Journal of Information Management, 66(4), 424-442. 
Rahman, M.S., Mannan, M., Hossain, M.A., Zaman, M.H., \& Hassan, H. (2018). Tacit knowledge-sharing behavior among the academic staff: Trust, self-efficacy, motivation and Big Five personality traits embedded model. International Journal of Educational Management, 32(5), 761-782.

Renzl, B. (2008). Trust in management and knowledge sharing: The mediating effects of fear and knowledge documentation. The International Journal of Management Science, 36, 206-220.

Ryan, S., \& O'Connor, R. (2013). Acquiring and sharing tacit knowledge in software development teams: An empirical study. Information and Software Technology, 55(9), 1614-1624.

Saini, M., Arif, M., \&Kulonda, D.J. (2018). Critical factors for transferring and sharing tacit knowledge within lean and agile construction processes. Construction Innovation, 18(1), 64-89.

Sasaki, Y. (2017). A note on systems intelligence in knowledge management. The Learning Organization, 24(4), 236-244.

Scarso, E., \& Bolisani, E. (2010). Knowledge-based strategies for knowledge intensive business services: A multiple case-study of computer service companies. Electronic Journal of Knowledge Management, 8(1), 151-160.

Shujahat, M., Hussain, S., Javed, S., Malik, M.I., Thurasamy, R., \& Ali, J. (2017). Strategic management model with lens of knowledge management and competitive intelligence: A review approach. VINE Journal of Information and Knowledge Management Systems, 47(1), 55-93.

Venkitachalam, K., \& Busch, P. (2012). Tacit knowledge: Review and possible research directions. Journal of Knowledge Management, 16(2), 357-372.

Wah, (1996b); cited in McAdam, R., Mason, B., \& McCrory, J. (2007). Exploiting the dichotomies within the tacit knowledge literature: Towards a process of tacit knowing in organizations. Journal of Knowledge Management, 11(2), 43-59.

Wahda, W. (2017). Mediating effect of knowledge management on organizational learning culture toward organization performance. Journal of Management Development, 36(7), 846-858.

Wyatt, J.C. (2001). Management of explicit and tacit knowledge. Journal of the Royale Society of Medicine, 94, 69.

Yeung, G. (2009). How Banks in China Make Lending Decisions. Journal of Contemporary Chin, 59(1), 285-302.

Zhang, X., Long, C., Wang, Y., \& Tang, G. (2015). The impact of employees' relationships on tacit knowledge sharing. Chinese Management Studies, 9(4), 611-625

\section{Annexure I: Questionnaire}

\begin{tabular}{|l|l|l|}
\hline 1 & KCR-1 & $\begin{array}{l}\text { I use my professional knowledge to assess financial capacity } \\
\text { of borrowers. }\end{array}$ \\
\hline 2 & KCR-2 & $\begin{array}{l}\text { I use my professional knowledge to assess managerial } \\
\text { capacity of borrowers. }\end{array}$ \\
\hline 3 & KCR-3 & $\begin{array}{l}\text { I want to know more about loan repayment capacity of } \\
\text { borrowers. }\end{array}$ \\
\hline 4 & KR-1 & $\begin{array}{l}\text { As I deal borrowers for longer period of time, therefore, } \\
\text { financial position of borrowers is known to me. }\end{array}$ \\
\hline 5 & KCR-4 & $\begin{array}{l}\text { During the process of credit appraisal, I want to know } \\
\text { resources of borrowers to pay back loan. }\end{array}$ \\
\hline 6 & & $\begin{array}{l}\text { I come to know background of borrowers when I interact for } \\
\text { recovery. }\end{array}$ \\
\hline 7 & & $\begin{array}{l}\text { I come to know repayment behavior of borrowers during } \\
\text { recovery process. }\end{array}$ \\
\hline 8 & KR-2 & I am aware of market reputation of borrowers. \\
\hline
\end{tabular}




\begin{tabular}{|c|c|c|}
\hline 9 & KR-3 & $\begin{array}{l}\text { I am sometimes aware of repayment behavior of borrowers } \\
\text { with other financial institutions. }\end{array}$ \\
\hline 10 & $\begin{array}{l}\text { KAUL- } \\
1\end{array}$ & I want to judge purpose of loan. \\
\hline 11 & $\begin{array}{l}\text { KAUL- } \\
2\end{array}$ & I come to know, how borrowers actually use loan amounts. \\
\hline 12 & & I come to know, how borrowers misuse loan amounts. \\
\hline 13 & KO-1 & $\begin{array}{l}\text { I come to know, about actual title of assets financed when I } \\
\text { enforce recovery measures. }\end{array}$ \\
\hline 14 & $\mathrm{KO}-2$ & $\begin{array}{l}\text { I come to know, about actual title of assets taken as collateral } \\
\text { when I enforce recovery measures. }\end{array}$ \\
\hline 15 & & I have an idea of price of assets subject to finance. \\
\hline 16 & & I have an idea of Forced Sale Value (FSV) of assets. \\
\hline 17 & KCD-1 & $\begin{array}{l}\text { It is necessary for me to establish identity of a borrower } \\
\text { before sanction of loan. }\end{array}$ \\
\hline 18 & & $\begin{array}{l}\text { I provide important information to management regarding } \\
\text { identification of borrowers before sanction of loan. }\end{array}$ \\
\hline 19 & CK-1 & I know context of loans. \\
\hline 20 & UKD-1 & $\begin{array}{l}\text { I use my knowledge about different business sectors for credit } \\
\text { decision making. }\end{array}$ \\
\hline 21 & UKD-2 & $\begin{array}{l}\text { I consider the characteristics of different geographical areas } \\
\text { for credit decision making. }\end{array}$ \\
\hline 22 & UKD-3 & $\begin{array}{l}\text { I consider family background of borrowers for credit decision } \\
\text { making. }\end{array}$ \\
\hline 23 & UKD-4 & $\begin{array}{l}\text { I use my knowledge of assets to be financed during credit } \\
\text { decisions. }\end{array}$ \\
\hline 24 & & $\begin{array}{l}\text { I consider nature of collateral securities during credit decision } \\
\text { making. }\end{array}$ \\
\hline 25 & & I have short time to give important credit decisions. \\
\hline 26 & & $\begin{array}{l}\text { Loans are recovered over the period of time allowed as per } \\
\text { sanction. }\end{array}$ \\
\hline 27 & & $\begin{array}{l}\text { During the credit process, there are many occasions when I } \\
\text { learns maximum about borrowers. }\end{array}$ \\
\hline 28 & & $\begin{array}{l}\text { My knowledge about context of cases of loans is useful for } \\
\text { recovery. }\end{array}$ \\
\hline 29 & KCD-2 & $\begin{array}{l}\text { There are many occasions to learn during process of recovery } \\
\text { of loans. }\end{array}$ \\
\hline 30 & KCD-3 & $\begin{array}{l}\text { Knowledge gained through learning in processes of recovery } \\
\text { is useful for credit decision making in future. }\end{array}$ \\
\hline 31 & $\mathrm{KCD}-4$ & $\begin{array}{l}\text { I deal with different internal and external communities during } \\
\text { recovery process. }\end{array}$ \\
\hline 32 & & $\begin{array}{l}\text { The enforceability of documents at law is actually tested } \\
\text { during recovery process. }\end{array}$ \\
\hline 33 & CK-2 & I have undocumented knowledge about insurance matters. \\
\hline 34 & & I have useful knowledge about litigation processes. \\
\hline 35 & VK-1 & My knowledge about litigation processes is not documented. \\
\hline
\end{tabular}




\begin{tabular}{|l|l|l|}
\hline 36 & & I have a lot of knowledge about post litigation processes. \\
\hline 37 & VK-2 & $\begin{array}{l}\text { Knowledge of my lawyers about post litigation processes is } \\
\text { not documented. }\end{array}$ \\
\hline 38 & VK-3 & $\begin{array}{l}\text { I have different types of knowledge about the borrower that is } \\
\text { not documented. }\end{array}$ \\
\hline 39 & VK-4 & $\begin{array}{l}\text { Undocumented knowledge possessed by credit and recovery } \\
\text { personnel is valuable asset for a bank. }\end{array}$ \\
\hline 40 & KCD-5 & Recovery of loans is very important for a bank. \\
\hline 41 & & Survival of bank is based on recovery of loans. \\
\hline
\end{tabular}


